Revue d'histoire de l'Amérique française

REVUE D.HISTOIRE DE L'AMÉRIQUE FRANÇAISE

\title{
ROBIDOUX, Réjean, Connaissance de Nelligan. Montréal, Fides, coll. « Le Vaisseau d’or », 1992. 186 p.
}

\section{Réginald Hamel}

Volume 46, numéro 4, printemps 1993

URI : https://id.erudit.org/iderudit/305167ar

DOI : https://doi.org/10.7202/305167ar

Aller au sommaire du numéro

Éditeur(s)

Institut d'histoire de l'Amérique française

ISSN

0035-2357 (imprimé)

1492-1383 (numérique)

Découvrir la revue

Citer ce compte rendu

Hamel, R. (1993). Compte rendu de [ROBIDOUX, Réjean, Connaissance de Nelligan. Montréal, Fides, coll. « Le Vaisseau d'or », 1992. 186 p.] Revue

d'histoire de l'Amérique française, 46(4), 699-701.

https://doi.org/10.7202/305167ar d'utilisation que vous pouvez consulter en ligne.

https://apropos.erudit.org/fr/usagers/politique-dutilisation/ 
ROBIDOUX, Réjean, Connaissance de Nelligan. Montréal, Fides, coll. «Le Vaisseau d'or», 1992. $186 \mathrm{p}$.

Connaissance de Nelligan de Réjean Robidoux, c'est un quart de siècle d'histoire littéraire autour de l'«Affaire Nelligan». Depuis les années 1960, j'en ai vécu tous les moments, toutes les étapes. En effet, du 14 au 25 novembre 1966, j'enregistrais à l'Université McGill un colloque sur Émile Nelligan. Participaient à ce colloque les Duhamel, Lortie, Lacourcière, Garon, Lauzière, Deschamps, Vigneault, Vachon, Leduc, Robidoux, Brault, Jones, Bessette, Lebel et tout particulièrement Clément Rosset. Ce dernier avait fait suer l'intelligentsia universitaire québécoise lorsqu'il avait déclaré que c'étaient les Canadiens français (plus ou moins fous) qui étaient responsables de la folie de notre gloire nationale. Je me souviens encore du remue-ménage dans un département des lettres où de jeunes collègues français n'en finissaient plus d'inventer des formules heureuses qui désavouassent les propos du dit Rosset. Comme j'avais le sens de l'histoire j'ai sauvé les bandes magnétiques de ce colloque lors du démantèlement «sauvage» (14 juillet 1969) de mon centre de documentation, et je les ai déposées à l'Université d'Ottawa. S'agissait-il de l'une de ces querelles idéologiques portant sur l'inclinaison des virgules? Même pas! C'était beaucoup plus prosaïque. Il s'agissait à cette époque déjà d'une démarche quasi viscérable, ayant pour but de faire triompher le «Fast Food» du savoir «instant» sur celui de la recherche qualifiée «d'Universitaire».

Robidoux reprend donc dans son ouvrage qui se veut polémique, point par point, toutes les inepties qui furent écrites depuis 1960 sur le «cas» Nelligan.

Après les immenses travaux de Wyczynski, il faut reconnaître que l'Université d'Ottawa, dans la foulée des travaux de Lacourcière (Laval), a acquis une bonne longueur d'avance sur les autres universités canadiennes. Ainsi n'est-il pas étonnant de retrouver sous la plume de Robidoux cette phrase-programme: «... au terme d'une longue cohabitation critique avec le tandem Nelligan/Dantin, je veux rendre justice à l'un et à l'autre, et les maintenir associés dans une unité littéralement indémaillable.» (p. 180) 
Connaissance de Nelligan comporte 13 chapitres en quatre parties: L'opus mirandum; le texte nelliganien; mythe et réalité; Nelligan et Dantin. Bien qu'il s'agisse d'articles et de conférences déjà publiés «sur plus de vingt-cinq ans», Robidoux est tellement habité par son sujet que sa pensée s'élabore sans faille. Il faut d'ores et déjà reconnaître qu'une telle démarche n'est pas commune chez nos critiques littéraires.

Des répétitions et des dilutions? Peu ou prou, c'est-à-dire tout juste assez pour signaler à son lecteur qu'il n'a pas perdu le fil du sujet.

Pour bien mesurer l'intégrité critique de Robidoux, je me suis donné la peine de relire les travaux de Vachon, Larose, Courteau, Nantais/Tremblay et de revoir Nelligan/un opéra romantique, pour conclure qu'il n'a rien laissé au hasard.

Dans les années 1960, le docteur Boulanger (psychiatre) avait rédigé une thèse à Paris sur l'équilibre mental de certains poètes dont Baudelaire et Nelligan; mais comme ses travaux n'avaient rien du sensationnalisme tant prisé de nos aristarques de l'édition, il n'avait pas réussi à trouver preneur, même pas chez Jacques Hébert. Aussi suis-je étonné que Robidoux, dans son chapitre «La signification de Nelligan» (p. 45-69), trouve remarquable (à juste titre) l'analyse psycho-critique de Gérard Bessette sur l'œuvre de Nelligan et qu'avec la même encre, il trouve que la socio-critique de Georges-André Vachon est fondée sur un «apriorisme extra-littéraire». Bessette serait-il plus versé en psychiatrie que Vachon en sociologie? Ces diverses approches me paraissent plutôt complémentaires et non en opposition les unes par rapport aux autres. De toute façon ces coups de griffes inter-universitaires ne diminuent en rien la portée intrinsèque de l'ouvrage de Robidoux.

Là où il marque incontestablement des points, c'est dans son examen minutieux et serré des écrits de Larose, de Courteau, de Nantais/Tremblay et cie. Je ne m'attarderai que brièvement sur Dantin; j'y ai été intimement mêlé en 1965 . À cet égard Robidoux a parfaitement raison d'affirmer que de traiter la critique de Dantin de «dantineuse», etc. etc., c'est non seulement se faire du capital littéraire à bon marché, c'est aussi faire un affront à l'histoire. Pour s'en rendre compte, il faut relire la correspondance de Dantin à Louvigny de Montigny que j'avais obtenue de Gustave Lanctôt (et du docteur Nadeau) et que j'ai fait paraître dans le Devoir (avril 1965). Cette finesse intellectuelle de Dantin me fut à maintes reprises confirmée par Jovette Bernier, Alonzo Cinq-Mars et Gabriel Nadeau qui étaient de ses intimes. J'ai fréquenté Jovette durant de nombreuses années et elle a eu l'amabilité de me laisser lire plusieurs textes inédits de Dantin - ainsi que d'autres correspondances dont celle de Borduas - et tous les propos littéraires de Dantin auraient mérité d'être publiés «ne varietur». Il est peu probable et très peu vraisemblable que Dantin ait «castré» les écrits de Nelligan lors de la préparation de la première édition (1902-1904). Là encore, je suis bien au courant de ces événements car j'ai eu accès aux manuscrits de Charles Gill dont j'ai réuni les œuvres en plusieurs tomes. S'il y avait eu magouillage, Gill n'aurait pas hésité à le dénoncer, bien au contraire: «la critique littéraire la plus impartiale, écrit-il au 
sujet de Dantin, la plus complète et la plus juste que jamais un Canadien ait faite de poésies canadiennes» (Euvres complètes de Gill, 2: 240).

Je ne puis que m'étonner avec Robidoux que «les écrits rocambolesques» sur Nelligan, attirent plus la critique «à chaud» et peut-être «à froid» que la critique qualifiée dédaigneusement «d'universitaire»; et je peux aussi me demander avec lui «à bon droit jusqu'où ira encore la critique québécoise?» (p. 168).

Enfin, quoique ce petit ouvrage de Robidoux soit remarquable à bien des points de vue, j'ai bien peur qu'il n'ait que le sort d'autres bons écrits historiques parus ces dernières années et qui demeurent des «voix dans le désert», au Québec où l'éloge de la médiocrité et de l' «àpeuprèsisme» a bien meilleur goût.

Département d'études françaises 